Boise State University

ScholarWorks

4-1-2017

The Gestalt of Revision: Commentary on "Return to the Typewriter"

Bruce Ballenger

Boise State University 


\section{The Gestalt of Revision}

\section{COMMENTARY ON “RETURN TO THE TYPEWRITER”}

BRUCE BALLENGER

he late Donald Murray, considered by many as one of America's greatest writing teachers, used to say that writers, despite their best intentions, often keep telling the same story over and over again. For me, it is the story of the wronged son. Somehow nearly every personal essay I write seems to find its way back to that theme, no matter how much I hope to send it in other directions. "Return to the Typewriter" was no exception. Even an essay about collecting manual typewriters had to be about my sad, alcoholic father and the wounds I suffered from his drinking. I think personal essayists are obligated to recognize these master narratives when they appear in their work, and to view them with suspicion.

Despite my vigilance about this, it took another reader to help me to see that I had once again surrendered a draft to that familiar theme. Carrie, a colleague and friend who knows my work, met me at a coffee shop in Boise to talk about "Return to the Typewriter," and quickly turned to this line, about midway through the draft: "It's likely I'm more attuned to the typewriter's crude rhythms because as a child I often went to sleep to the sound of my father pounding away on his Royal Standard in a room down the hall. The sound was a lullaby because it meant my father wasn't too drunk to type, and as I lay there in the dark I could believe him again when he said he was a writer." Many pages later, the draft ended with a line that continued the thought, suggesting that the sound of typing is the sound of hope. My decision to end the draft that way signaled, unambiguously, that the piece was about trying to heal the same old wound.

"I'm not sure, Bruce, but I don't really think this essay is about your father," 
she said, leaning over her coffee cup. "I mean it might be, I guess, but that's not how I read it." I knew immediately she was right, and that the revision must begin by wrestling with the question of meaning. If not the story of the wronged son, what was this typewriter essay about?

I was asking myself the question I often put to my students, one that I usually phrase tactfully, making a query about the "theme" or "big idea" behind a draft. But behind this is always a more indelicate question, one that is both essential and risky: "So what?" It is essential because works of nonfiction should have a clear and often explicit purpose, but it's also a risk to nail this down too soon. A rush to judgment about the meaning of a work can turn a theme into a thesis, which becomes a club that beats the material into submission before writers have a chance to discover what they didn't know they knew. And yet, an essay must be about something. There has to be some kind of idea or question that animates the work, some thread that runs through it and makes it whole.

I don't think we're very good at talking about the problem of unity in creative work, which seems strange because it's so important. Part of the challenge is the relatively impoverished language we have to talk about it, at least in writing. Somehow even "theme" seems too much like "thesis" - it feels reductive and overly simplistic, like a suitcase into which the material must be neatly folded. This goes against our sense that the work, like the fragments of experience it captures, is much unrulier than that. No amount of jumping up and down on the suitcase is enough to close the latch. But I also think that writers sometimes even resist the idea of unity, especially if it is explicit; these writers think that readers should be able to intuit a theme, and if it happens to differ from the one intended, so much the better.

I'd argue that in most creative nonfiction the writer's intentions do matter, a lot. It was on this point that Scott Sanders, in his wonderful essay on the essay "The Singular First Person," seemed most emphatic. When a scholar confused one of his essays about his childhood on a military base as a work of fiction, Sanders complained that "I was writing about the actual, not the made up," and argued that he intended something quite different by writing an essay about his experiences than he might had he written a short story. It mattered to him that those intentions were clear to his readers, an idea Sanders realized is subverted by the doctrine of intentional fallacy, which is often celebrated by critics and some writers. "I think quite recklessly of intention all the time," 
Sanders wrote. "I believe that if we allow the question of intent in the case of murder, we should allow it in literature." Of course, an absence of clear intention wasn't the problem in the draft of "Return to the Typewriter." The problem was that the meanings I seemed to intend in the draft rang the same old thematic bell. But how should I revise the work to find fresh insight? And in particular, how could I see what the whole work might try to do?

As part of a research project, I've been interviewing advanced writing students, undergraduate and graduate, about their revision practices. One of the things that struck me is how intensively even experienced writers (some of them MFA students) focus on revising the parts of a draft, and often struggle to see how those parts relate to the whole. For example, here's a metaphor that Alex, a senior English major, used to describe how he understands the process of revision: "I have a friend who was a cyclist, and he said if I were on my bike and if the seat was a centimeter or two higher or lower, I would definitely notice it. It wouldn't just affect the seat height but it would affect my reach from the shoulder to where you grasp the handle bars. I took that story ... that small changes can really reshape the piece." What's interesting about Alex's metaphor is his instinct-shared by most of the writers I talked to- - that revision begins with the parts: adjust the seat and the whole bike will ride differently. For these writers, a rewrite begins and often ends by focusing on reworking paragraphs, sentences, words. The writers I interviewed rarely work the other way, from the whole to the parts.
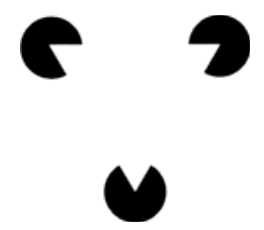

Gestalt theory suggests that you begin not with the height of the seat or even the ride of the bike, but the direction in which it's being steered. One of the celebrated images that theorists use to explain the Gestalt theory of perception is this one, a triangle that is defined at each corner by a black dot. In the absence of the triangle, the dots look like Pac-Men figures or partially eaten pies-they have completely different meanings. But when we see the triangle, the dots' significance shifts-their meaning is integral to the emergence of the figure. A key here for the Gestalt theorist (and I'm hardly 
an expert) is that the whole defines the parts, and not the other way around. What this suggests to me as a writer is that in revision we must first try to see the "triangleness" of our drafts - the key idea, question, theme, feeling, or even image - that seems to best capture our purpose for the whole composition.

I've been playing around recently with how Gestalt theories of perception might help writers to literally see their drafts. It's not as crazy as it sounds. For example, the inverted pyramid, a commonplace in beginning journalism classes, is a visual representation of the structure of the hard news article. It works from the principle that the most important information comes first, the least important last. Freytag's triangle, which captures the rising and falling action in a narrative, helps writers imagine how a story might be visualized over time. Most written compositions, especially stories, also have a beginning, middle, and end, and information is distributed between them. Typically, roughly a quarter of the material is devoted to the beginning, half to the middle, and a quarter to the end.

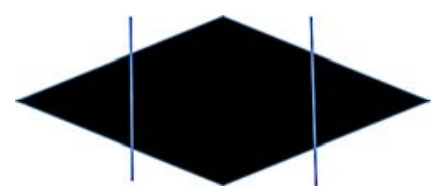

Admittedly, what these images offer is insight about structure rather than meaning (see Tim Bascom's "Seeing the Perfect Essay" for his insightful take on this), but they do focus a writer's gaze on the architecture of the whole draft rather than the engineering of a sentence or paragraph.

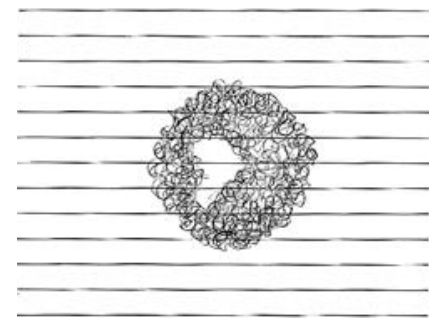

When I've asked my students to see their drafts visually- to actually draw what they look like-they must often resort to metaphor. Here's what one of my students drew to describe a draft about the recent loss of her father. When I asked her about the sketch, Aeshah told me that "when I was drawing this 
I think the drawing represents the complications of feelings, or the mixed feelings, about this piece. It represents whatever I wrote about him, that it's not enough." Symbolically, then, this tangle of lines that whirl around each other stand in for the complexity of her feelings about her subject. The empty spaces represent what is left unsaid, and perhaps what never can be said. I'm not exactly sure whether this helps her with the revision, though it does poignantly clarify her feelings about the draft, which at least flags the emotional work the rewrite might demand.

Maybe more relevant to seeing the thematic heart of a draft (or its absence) is the Gestalt principle of "closure." This is the idea that when confronted with what seem at first random parts or images, the human mind looks for recognizable patterns. It's a principle that is often illustrated with the triangle image I shared earlier. Notice that in the graphic we see a triangle that isn't actually drawn for us. It is one we mentally create in an effort to make sense of an image that, at first, appears to be nonsensical-just three hungry Pac-Men facing off in a field of white space. I think that experienced writers intuitively seek closure in their work. They search for the missing figure in all the assembled parts-that idea, feeling, or question that gives those parts meaning by putting them in relationship with each other. But the Gestalt theory of closure also suggests that the shapes we will search for are the ones we know. This, of course, was exactly the problem with the draft of "Return to the Typewriter."

I think most rewrites must begin with, as Sanders put it, a "reckless" reexamination of intention. We should unsettle the provisional meanings that emerge in a draft, especially when they sound familiar. My typical strategy for doing this-and the one I used to rewrite "Return to the Typewriter"-is to begin a revision by looking in the places in a personal essay where the meanings are most concentrated: the lines and passages where I take reflective turns, but especially the last paragraphs. In contrast with many academic articles, essays are end-weighted with meaning. Because the motive is to find out, rather than to prove, insights emerge late, the caboose at the end of a train of thought. It was the very last sentence that most signaled my intention in the draft. Reflecting on the strange appeal of the manual typewriter for me, I wrote that "it is the sound of the machinery of meaning-making-rat a tat, tat, rat a tat, tat, tat, ding - then the sweep of the left hand and the grind of the carriage as it returns home to begin a fresh line. It is the hopeful sound 
of typing down the hall." No, I thought, that isn't it. The question driving my interest in writing this piece wasn't really how typewriters remind me of my father. It is about my odd impulse to collect the things. So I did more research on the psychology of collecting and began the draft again from the beginning.

In "The Interplay of Form and Content in Creative Nonfiction," Eileen Pollack writes that it is "the interplay between the central question that guides a writer's research and the form that helps that writer organize his or her findings" that "is at the living, breathing heart of creative nonfiction." The "central question," perhaps even more than the theme, best captures an essayist's intentions, and that's where we must begin to see the whole that might give new meaning to the parts. However, I still puzzle over the possibilities of revision as a problem of perception. Though my experiments with asking students to draw a draft are inconclusive, Cheryl, a graduate student, told me recently that she has taken to taping each page of a draft manuscript on the wall and looking at them from a distance, a practice she apparently shares with literary journalist Gay Talese. I wonder what she sees. "Continuation," another Gestalt principle of perception, suggests that in an image our eyes look for the line and attempt to follow it, and "when the line ends, the eye keeps going." Maybe Cheryl sees something beyond that line of white manuscript pages taped to the wall, a shape that looks like this

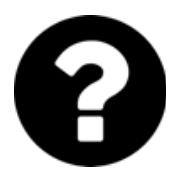

because it is where the line ends that writers must begin again. 